\title{
Role of Vitrons in Alkali Silicate Binary Glasses
}

\author{
Leroy W. Tilton
}

\begin{abstract}
Applications of vitron theory to analyses of properties of $\mathrm{R}_{2} \mathrm{O}$ silicate binary glasses indicate that changes in slope on the property-composition curves may occur where there are integral numbers of cations per dodecahedral cavity or cage of the network. From geometrical considerations it is found that 1 or 2 oxygens and 6 sodiums can be accommodated inside a cage, and similarly not more than 1 oxygen and 4 potassiums can be inclosed in a cage.

Data on chemical attack and on solubility losses in water suggest for alkali silicate glasses a maximal average inclosure of oxygen inside the cavities at 16.7 -mole percent for $\mathrm{K}_{2} \mathrm{O}, 23.1$ percent for $\mathrm{Na}_{2} \mathrm{O}$, and probably 28.6 percent for $\mathrm{Li}_{2} \mathrm{O}$. These compositions correspond to 1 , 1.5 , and 2 oxygens per cage. These compositions mark the beginning deterioration of the net, possibly because of nonbridging oxygen. Changes in rate of volatilization occur at 28.6-, 37.5-, and 50.0-percent $\mathrm{R}_{2} \mathrm{O}$ for potash, soda, and lithia silicate glasses, respectively. These critical compositions are considered those for which the cavities in the glasses are completely saturated with the modifier oxides, $\mathrm{R}_{2} \mathrm{O}$, and with additional cations, $R$.

Detailed analyses of curves of molar volume versus composition show that the critical points for oxide saturation are evident and that changes in slope may occur at other critical compositions corresponding to integral numbers of cations per cage. It is found that the percentage of 16.7-percent $\mathrm{Na}_{2} \mathrm{O}$ at high temperatures and the saturation point of 37.5 percent at low temperatures are critical in curves for specific (electrical) resistance. The "deep-well" point at 16.7-percent $\mathrm{Na}_{2} \mathrm{O}$ critically separates soda silicate glasses that are very readily devitrified from those that contain more oxide modifier and are more stable.
\end{abstract}

\section{Introduction}

A noncrystal ionic model for silica glass was constructed by the writer and described at the annual meeting of the Optical Society of America in October 1956. He simultaneously announced a new concept applicable to studies of glasses, namely a small, stressed microstructure having near crystal symmetries and almost capable of forming macrocrystals. The particular structure found to accord with many data on fused silica glass consists of clusters of distorted pentagonal dodecahedra, called vitrons, having as subunits the well-known siliconoxygen tetrahedra. A four element vitron is represented in figure 1.

The most important characteristic of the proposed vitrons is the fivefold symmetry which is incompatible with the formation of macrocrystals. See figure 2. A second important feature is a balanced distribution of stresses and bond strengths. Within each vitron (clusters of dodecahedral cages) the bonds are very strong at the center but weak at the peripheries where high-tangential tensions and lowered force constants are automatically limiting the growth potential.

In a previous paper [1] the author shows how the properties of silica glass, including density, differential diffusion of gases, interatomic distances, low tensile strengths, unusual (reversible) temperature and pressure effects on volume, irreversible heat effects, and internal friction at low temperatures can be better understood according to the vitron theory which can be considered as a modification of existing theories in such manner as to reconcile and amplify them.

Reported in part at the Annual Meeting o the Optical Society of America, Abstract F4, J. Opt. Soc. Am. 47, 115 (1957)
It is suggested that vitrons grow simultaneously throughout a melt of glass at very high temperatures and become more or less imperfectly united through common pentagonal faces or occasional oxygen bridges between unsatisfied silicon atoms in adjacent vitrons. Smaller vitrons could grow in the inter-

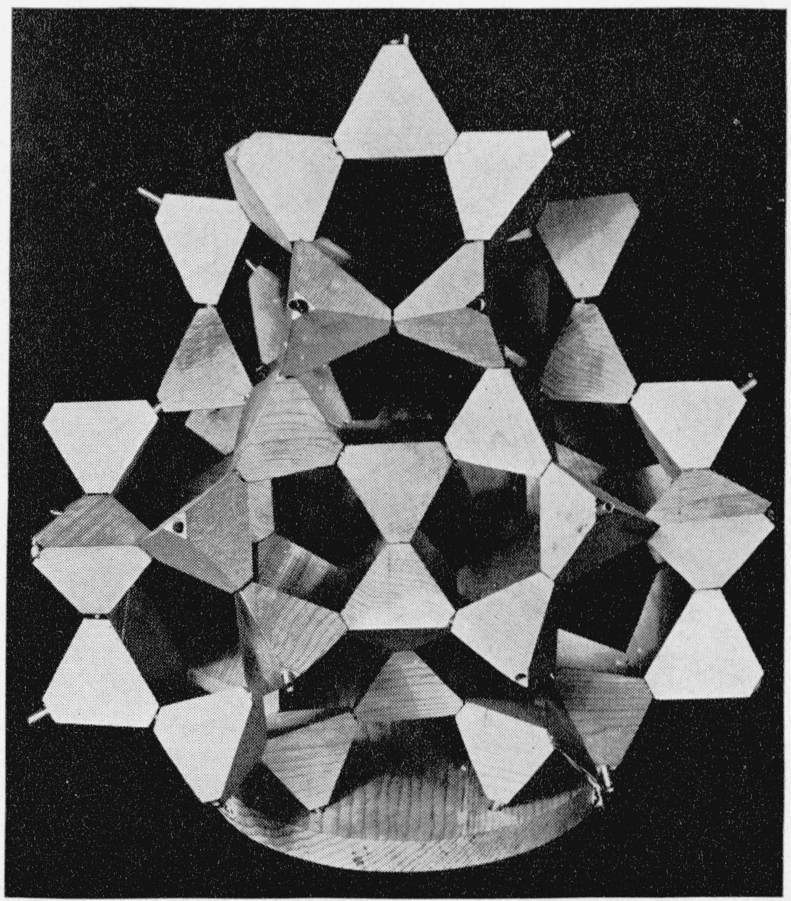

Figure 1. Off-axis view of model of completed 4-element vitron (type 4, tetrahedral)

Coiled wire springs indicate extra $\mathrm{O}^{-}$charges and vacant tetrahedral corners indicate $\mathrm{Si}^{+}$charges available for attachments to other vitrons by oxygen bridges. At center foreground is a reentrant three-face that can unite with another vitron presenting a similar three-face. 

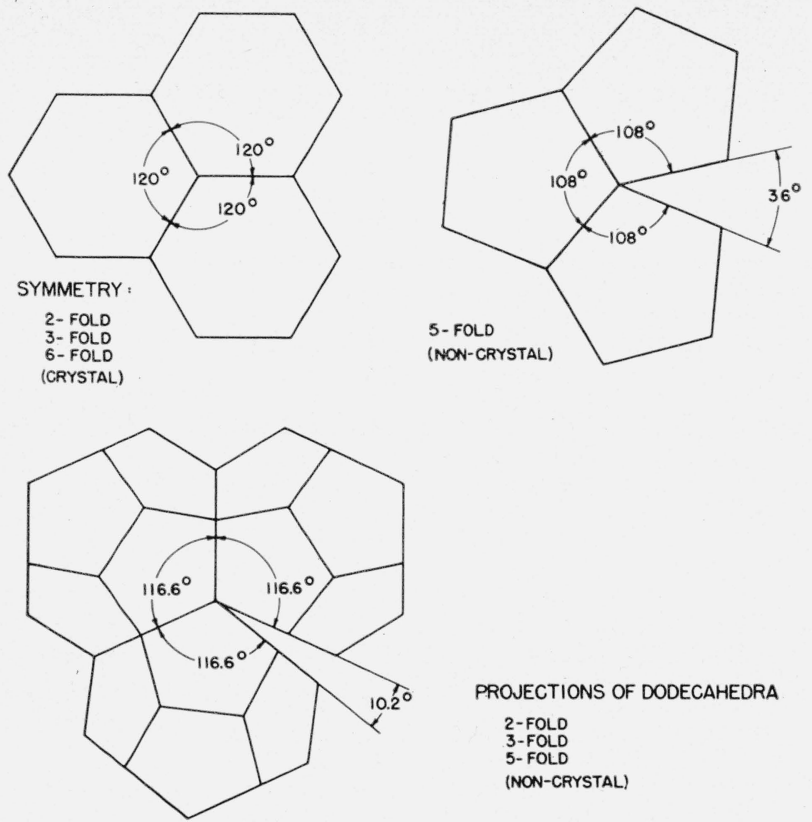

PROJECTIONS OF DODECAHEDRA 2-FOLD
3-FOLD
5-FOLD

(NON-CRYSTAL)

Figure 2. Crystal and noncrystal clustering.

Just as pentagonal tiles fail where hexagons succeed in corering a floor, so do regular pentradodecahedra fail to fill space completely and extensively. By radial compression, the neighboring dodecahedra may be distorted and meet each other and thus a limited degree of growth in space is possible.

stices between larger vitrons. A single-element vitron is only $8 \mathrm{~A}$ in diameter (on centers) and an upper limit for vitron dimensions may be approximately $30 \mathrm{~A}$.

The next step in testing the vitron theory is an application to binary glasses, and of these the simplest and best known are the alkali silicates. This paper is a reconnaissance study of simple potash, soda, and lithia silicate binary glasses by analyses of such limited and imperfect data as may now exist on the properties of such glasses as functions of the concentration of the respective modifiers.

The stepwise nature of changes in the properties of some binary glasses has been noticed and discussed by several investigators. In general, in such studies, there has been unfortunate emphasis on the possibility of the existence of chemical compounds that might cause discontinuities or sharp breaks in properties such as would be evidenced by the inter. section of straight-line segments. A more comprehensive view would give weight also to points of inflection, maxima and minima of ordinates or slopes, intersections of tangents, or other especially noticeable features not technically discontinuities Sometimes, also, there are tacit assumptions that a special feature at a given composition on the curve of one property should, in general, be found on the curves of other properties. Actually, of course, it must be recognized that a circumstance which definitely affects sensitive measures of volatility, for example, may leave no noticeable imprint on rate of change of density. Special points on a property curve for a given temperature range may necessarily be entirely absent at very different temperatures.
Vitron theory suggests causes other than compound formation for the existence of special points on property-composition curves. For example, some oxygen may enter the cages (cavities) together with its cation and there should be critical compositions at which, approximately, this oxide saturation is completed and the process of net deterioration by "unshared oxygen" begins. Then at other compositions the cavities should become completely saturated with additional cations. Also to be considered, although perhaps of less importance, are the compositions at which there are integral numbers of cations per cavity.

Among properties that have been found useful in this study are solubility, chemical attack, volatilization, molar volume, electrical resistance, and fluidity.

\section{Structural Characteristics of $\mathrm{R}_{2} \mathrm{O}$ Silicate Glasses}

Vitron theory has interestıng quantitativeaspects that may be used in applications to existing data.

\subsection{Numerical Distribution of Cations}

From the compositions expressed in mole proportions, it is easy to compute for the vitron model the numbers of cations per cavity. For the simple case of binary glasses with oxides $\mathrm{R}_{2} \mathrm{O}$ and $\mathrm{SiO}_{2}$ in the proportions $r$ and $s$ (where $r+s=1$ ), the number of cavities (or cages) is proportional to $s / 5$ and the silicon to oxygen ratio is $s /(2 s+r)$. It would seem that integral numbers of cations per cavity, $R_{h}$, may be significant for some purposes and the corresponding proportions of $\mathrm{R}_{2} \mathrm{O}$ are readily computed as $r=D_{h} /\left(R_{h}+10\right)$. Also, a maximum upper limiting value of the coordination number, $N_{c}$, is necessarily twice the ratio of oxygen to cation, $R$, and therefore $N_{c}=1+2 s / r$.

The stability of the network is estimated by computing for the average tetrahedron the number of corners that are securely tied into the net by the sharing of oxygens. On the conventional basis, the "shared oxygens" (half oxygens) per tetrahedron are computed as $\mathrm{O}_{s}=4-2 r / s$. This assumes that all oxygen added by the modifier oxide becomes attached to only one silicon and therefore is effective in weakening the network. If it be assumed that some oxygen as well as cation can be enclosed in the cages, insofar as their capacity and other conditions may permit, then the computation of shared oxygen is a multiple process, depending on the number, $\mathrm{O}_{i}$, of oxygens that may be inclosed as oxide inside the cages, and $\mathrm{O}_{s}=4+0.40 \mathrm{O}_{i}-2 r / s$. On this basis, the network will not start deteriorating until certain threshold values of added oxygen are reached. As compared with the conventional basis, $\mathrm{O}_{i}=0$, it then becomes easier to realize why some glasses with relatively high modifier content do not show marked instability even at compositions near those for which the glasses are commonly said to have sheet and chain structures of their tertahedra rather than veritable networks. 
Table 1 gives useful data for applying the vitron theory to simple binary glasses having modifier oxides of the type $\mathrm{R}_{2} \mathrm{O}$. It is suggested that above the horizontal dotted line in table 1 , devitrification may develop rapidly at relatively high temperatures because there is insufficient nonsilica inside the cages to effectively resist or impede the crystallization or contractural potential. In general, other glasses above the upper stepwise line should be stable, because the three-dimensional connections remain intact. Between the stepwise lines the network persists but is weakened. Below that region marked weaknesses may be manifest because spacial coherence of the network is not assured.

One of the most convincing proponents of the use of straight-line segments in representing the volume of glass as a function of composition is Huggins [2] who discussed details of possible structures in soda silicate glass and numerically designated 6 or 7 compositions where the property-composition curves showed, or might be expected to show, more or less abrupt changes in slope. As shown in the last columns of table 1, the points designated by Huggins are in close agreement with the compositions at which vitron theory finds for $\mathrm{R}_{2} \mathrm{O}$ silicate glasses that the numbers of cations per hole in the net are $3,5,6,8$, 9 , and 10. At these degrees of saturation or supersaturation for alkali silicate binary glasses, it will be shown below that changes in slope of certain property-composition curves may occur.

\subsection{Geometrical Evidence}

It has long been assumed that most cations introduced in silicate glasses in small proportions are located within the cavities of the network. In a glass of 16.7 mole percent $\mathrm{Na}_{2} \mathrm{O}$, there are 2 atoms of sodium per cavity or cage according to the vitron theory (see table 1). It is logical to expect that each cation will be found in closest possible contact with 3 oxygens of a single silicon-oxygen tetrahedron and this basic assumption underlies this analysis. It is further assumed here that the first oxygen introduced into the melt by each pair of cations will also be found in a cage with its 2 cations. If 2 sodiums are on opposite sides of their oxygen, that is, if the 3 centers lie on a straight line (as might be expected in a high-temperature state of $\mathrm{Na}_{2} \mathrm{O}$ ), then their center line can coincide with any one of the 10 threefold axes of a cage. Further, if the effective radius of sodium is $0.93 \mathrm{~A}$, there is just sufficient space inside a cage to permit such an alinement (see fig. 13). Each $\mathrm{Na}$ will then be in contact with 4 oxygens and not far from 6 other oxygens. This unique arrangement is the "deep-potential-well" condition for soda in silica that is discussed in section 6 .

If the concentration of soda is higher than 16.7 mole percent, sodium atoms can occupy some of the 6 other positions which they could take and each be in contact with 4 oxygens and not far from 6 others. There will be only 8 (not 10 ) such positions available for $\mathrm{Na}$. That is, because of mutual interpenetration at nearest neighbor positions, the geometrical saturation of a symmetrical cage would be reached when only 4 of the 10 axes of threefold symmetry are simultaneously occupied by pairs of $\mathrm{Na}$ ions. If such geometrical saturation could be reached there would be $12(\mathrm{Na}-2 \mathrm{dNa})$ distances of $2.58 \mathrm{~A}$ and 12 of $3.66 \mathrm{~A}$ within each cavity. The distribution would be symmetrical with the 8 sodium ions at the corners of an inscribed cube. However, because of distortional flattening of the cages along a diameter directed radially with respect to the whole vitron of which it is a component, only $6 \mathrm{Na}$ per cage instead of 8 can be inclosed. Thus there will be only 6 internal distances of $2.58 \mathrm{~A}$ and 6 of $3.66 \mathrm{~A}$, and this degree of saturation will be reached at 37.5-mole percent $\mathrm{Na}_{2} \mathrm{O}$ as read from table 1 .

There is unique space inside the cages for only 1 oxygen but possibly 2 oxygens and their cations can be inclosed in some of the more oblate cages. The oxygen added, as modifier increases, need not necessarily begin to weaken the network immediately after the cages are saturated with 1 central oxygen because some of the added oxygen can locate partly in one cage and partly in another and still be in such close contact with its cation that it does not break

TABLE 1. Constitutional characteristics of $\mathrm{R}_{2} \mathrm{O}$ silicate binary glasses

\begin{tabular}{|c|c|c|c|c|c|c|c|c|c|c|c|c|c|c|}
\hline \multicolumn{2}{|c|}{ Molar composition } & \multicolumn{2}{|c|}{ Formula } & \multirow{3}{*}{ Cages $s / 5$} & \multirow{3}{*}{$\begin{array}{c}\text { Cations per } \\
\text { cavity } R_{h}\end{array}$} & \multirow{3}{*}{$\begin{array}{l}\text { Upper } \\
\text { limiting co- } \\
\text { ordination } \\
\text { with oxygen }\end{array}$} & \multirow{2}{*}{\multicolumn{5}{|c|}{$\begin{array}{c}\text { Shared oxygens, } \mathrm{O}_{s} \text { (connected tetra- } \\
\text { hedral corners) } \\
\text { Values of } \mathrm{O}_{j}\end{array}$}} & \multicolumn{3}{|c|}{ Special ratios of silicon to oxygen } \\
\hline \multirow{2}{*}{$\mathrm{R}_{2} \mathrm{O}$} & \multirow{2}{*}{$\mathrm{SiO}_{2}$} & \multirow{2}{*}{$\mathrm{R}_{2} \mathrm{O}$} & \multirow{2}{*}{$\mathrm{SiO}_{2}$} & & & & & & & & & \multirow{2}{*}{$\begin{array}{c}\text { Computed } \\
\text { from vitron } \\
\text { model }\end{array}$} & \multicolumn{2}{|c|}{ Found by Huggins [2] } \\
\hline & & & & & & & 0 & 1 & 2 & 3 & 4 & & 1940 & 1954 \\
\hline 0.000 & 1.00 & 0 & 5 & 0.200 & 0 & & $-4.0-$ & 4. 0 & 4. 0 & 4. 0 & 4. 0 & 0.50 & 0.50 & 0.50 \\
\hline .091 & 0.909 & 0.5 & 5 & .182 & 1 & 21.0 & 3.8 & 4.0 & 4. 0 & 4. 0 & 4. 0 & 476 & & \\
\hline .167 & .833 & 1 & 5 & .167 & 2 & 11.0 & -3.6 & $-4.0=$ & -4.0 & -4.0 & -4.0 & .454 & & \\
\hline .231 & .769 & 1. 5 & 5 & .154 & 3 & 7.7 & 3.4 & 3.8 & 4.0 & 4. 0 & 4. 0 & .435 & .435 & .437 \\
\hline .286 & .714 & 2 & 5 & .143 & 4 & 6. 0 & 3.2 & 3. 6 & $-4.0=$ & 4. 0 & 4.0 & .417 & & \\
\hline .333 & .667 & 2.5 & 5 & .133 & 5 & 5.0 & $-3.0-$ & 3.4 & 3.8 & 4. 0 & 4.0 & .400 & .40 & .40 \\
\hline .375 & .625 & 3 & 5 & .125 & 6 & 4. 3 & 2.8 & 3. 2 & 3.6 & $-4.0-$ & 4. 0 & .385 & & $(0.375)$ \\
\hline .411 & .589 & 3.5 & 5 & .118 & 7 & 3.9 & 2.6 & $-3.0=$ & 3.4 & 3.8 & 4. 0 & .371 & & \\
\hline .444 & .556 & 4 & 5 & .111 & 8 & 3.5 & 2.4 & 2.8 & 3.2 & 3. 6 & $-4.0-$ & .357 & $\mathrm{a}(0.364)$ & $(0.357)$ \\
\hline .474 & .526 & 4. 5 & 5 & .105 & 9 & 3. 2 & 2. 2 & 2.6 & $-3.0=$ & 3.4 & 3.8 & .345 & 0.345 & \\
\hline .500 & .500 & 5 & 5 & .100 & 10 & 3.0 & 2. 0 & 2.4 & 2.8 & 3.2 & 3. 6 & .333 & $(0.333)$ & 0.333 \\
\hline$\cdots$ & $\cdots$ & $\cdots$ & $\cdots$ & $\cdots$ & $\cdots$ & $\cdots$ & $\cdots$ & $\cdots$ & $\cdots$ & $\cdots$ & $\cdots$ & $\cdots$ & ......... & -....... \\
\hline$\cdots$ & $\cdots$ & $\cdots$ & $\cdots$ & $\cdots$ & $\cdots$ & $\cdots$ & $\cdots$ & $\cdots$ & $\cdots$ & $\cdots$ & $\cdots$ & $\cdots$ & - & n \\
\hline 630 & 370 & $8 . \dot{5}$ & $\dot{5}$ & 074 & 17 & 2.2 & 0.6 & 10 & 1.4 & 1.8 & 22 & 270 & 0.27 & - \\
\hline
\end{tabular}

a Ratios in parentheses were less prominent or seem to be given less weight by Huggins. 
$\mathrm{Si}-\mathrm{O}$ bonds. Whenever bonds are broken the unshared oxygen can probably be located near the cations and maintain electrical neutrality within satis.factorily small volumes.

For potash silicate glasses the conditions are some. what similar, especially for low-cation content, but the $\mathrm{K}$ ion is so much larger than $\mathrm{Na}$ that the unique alinement of atoms in contact, with the oxygen center on one of the threefold axes, is impossible. The maximum angle, $\mathrm{K}-\mathrm{O}-\mathrm{K}$, for $\mathrm{K}_{2} \mathrm{O}$ inside a cavity would be about $80^{\circ}$ instead of $180^{\circ}$, as can occur for $\mathrm{Na}-\mathrm{O}-\mathrm{Na}$. The space inside a symmetrical cavity can accommodate 1 oxygen with 2 or with 3 K. Geometrically, the maximum $\mathrm{K}$ content is 4 per cage, even with no fully inclosed oxygen. In that case $\left(28.6 \% \mathrm{~K}_{2} \mathrm{O}\right)$, the $4 \mathrm{~K}$ atoms can form a tetrahedron within each cage and give 6 uniform $\mathrm{K}-\mathrm{K}$ distances of 2.8 A. An interesting question is: Can distortion of cages proceed to such extent that an oxygen can be included somewhere near the center and $4 \mathrm{~K}$ also be inclosed with a slightly reduced $\mathrm{K}-\mathrm{K}$ distance?

\subsection{Differential Diffraction Patterns}

Diffraction studies have been the principal direct and quantitative means of investigating the structure in glasses. Warren and his associates [3] pioneered in the construction of radial-distribution curves by means of Fourier transforms of the scattering curve for vitreous silica. Such curves give directly the distances from a silicon, or from an oxygen, to the near-neighbor atoms. This method has been applied to several soda-silicate glasses [4], to potash silicate glasses [5], and to some soda silicate glasses containing lime [6]. Such work has been done, also, on some simple borate glasses [7], and phosphate glasses [8].

The combined curves, however, become too crowded for resolution of pertinent peaks. Hartlief [5] seems first to have analyzed the radial-distribution curves by differential treatment in order to get resolution in the residual curves. He subtracted ordinates for a $\mathrm{SiO}_{2}$ curve from those for each of several potash silicate glasses and thus obtained separately, as residuals, the average radial distributions from a potassium atom in each of the potash silicate glasses. Lukesh [9] independently applied the differential process to existing data on soda silicate glasses, and Dietzel [10] also did this work.

As pointed out by Hartlief and by Dietzel, the peaks on the residual radial distribution curves do not shift with change in composition as much as should be expected if they are evidences of an average equitable distribution of cations throughout the melts. It is reasonable to conclude that the ions free to migrate randomly can contribute little or nothing to noticeable peaks on such curves, whereas those that are more or less fixed may give peaks that should be interpretable.

Even the relatively constant residual curves characteristic of a given type of cation in fixed locations, are not unambiguously interpretable because there are multiple cation-silicon and cation-oxygen distances as well as the cation-cation distances in which (for this analysis) the chief interest lies. Without some definite three-dimensional model to test, little progress can be made. With a model, however, it is not too difficult to decide whether the model is or is not in accord with the radial-distribution curves. In order to fairly compare proposed models with the results deduced from X-ray data, it is necessary to compute the distances (between centers) from any modifier cation to each position that a neighbor atom might logically be expected to occupy. See figure 3. Then some consideration must be given to the extent of probable shielding that might prevent detection of the various neighbors. This has been done for both soda silicate and potash silicate glasses, in undeformed cages of vitron, and the results are expressed in tables 2 and 3 , respectively (after elimination of some numerical results obviously impossible because of interpenetrations or gross shielding).

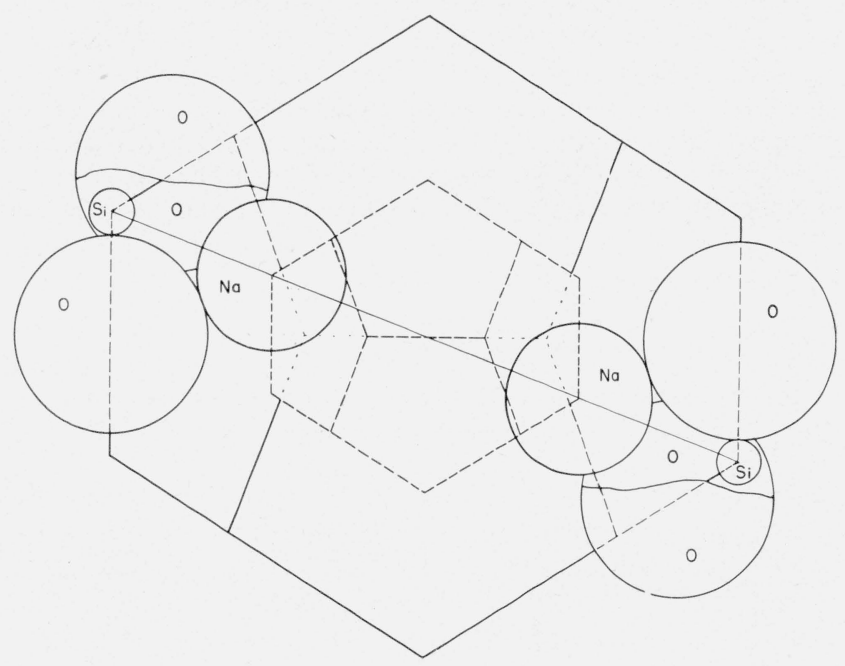

Figure 3. Loci of cations in dodecahedral cages of $\mathrm{SiO}_{2}$.

There are 10 axes through opposite Si centers, and cation centers can lie on these axes and be in direct contact with 4 oxygens and not far from 6 other oxygens.

In both types of glass it is indicated that the residual peaks on the curves deduced from X-ray diffraction are caused principally by nearest and next-nearest neighbors. Second, it was noticed that the modifier cation can be distributed uniformly not only within each cavity but also similarly distributed in adjacent cavities on threefold axes so oriented that many of the cations are distributed at approximately equal distances from each other over longer ranges than are attainable within a single cage. Such equal longer-range separations computed for the $\mathrm{Na}$ ions and the $\mathrm{K}$ ions in binary $\mathrm{R}_{2} \mathrm{O}$ silicate glasses approximate 6.2 and $6.5 \mathrm{~A}$, respectively, for low concentrations of the modifier cations. Similar equal separations approximating 4.9 and $4.8 \mathrm{~A}$ also can occur in increased numbers at high concentrations. 
TABLE 2. Radial distribution of ions around sodium in soda silicate glasses (angstroms)

\begin{tabular}{|c|c|c|c|c|c|c|c|}
\hline \multicolumn{3}{|c|}{ Computed possibilities } & \multirow[b]{2}{*}{$\begin{array}{l}\text { Vitron } \\
\text { model }\end{array}$} & \multirow[b]{2}{*}{$\begin{array}{l}\text { Remarks and estimates of } \\
\text { shielding }(s)\end{array}$} & \multirow[b]{2}{*}{$\begin{array}{l}\text { Estimated } \\
\text { peaks }\end{array}$} & \multicolumn{2}{|c|}{$\mathrm{X}$-ray evidence } \\
\hline To silicon & To oxygen & To sodium & & & & $\begin{array}{c}\text { Lukesh [9] } \\
\text { (Warren) } \\
\text { peaks }\end{array}$ & $\begin{array}{l}\text { Dietzel } \\
{[10] \text { peaks }}\end{array}$ \\
\hline $\begin{array}{c}1 \mathrm{Si}_{1 \mathrm{at}} \\
3 \mathrm{Si}_{2 \mathrm{~d}} \\
6 \mathrm{Si}_{3 \mathrm{~d}} \\
\\
\end{array}$ & $\begin{array}{c}4 \mathrm{O}_{1 \mathrm{st}} \\
6 \mathrm{O}_{2 \mathrm{~d}} \\
3 \mathrm{O}_{3 \mathrm{~d}} \\
6 \mathrm{O}_{4 \mathrm{th}} \\
3 \mathrm{O}_{5 \mathrm{th}} \\
6 \mathrm{O}_{6 \mathrm{th}} \\
\end{array}$ & $\begin{array}{r}6 \mathrm{Na}_{2 \mathrm{~d}} \\
6 \mathrm{Na}_{3 \mathrm{~d}} \\
3 \mathrm{Na}_{\text {ext }} \\
6 \mathrm{Na}_{\text {ext }} \\
1 \mathrm{Na}_{4 \mathrm{th}} \\
6 \mathrm{Na}_{\text {ext }} \\
3 \mathrm{Na}_{\text {ext }} \\
12 \mathrm{Na}_{\text {ext }} \\
12 \mathrm{Na}_{\text {ext }} \\
12 \mathrm{Na}_{\text {ext }}\end{array}$ & $\begin{array}{l}\text { 2. } 24 \\
2.25 \\
2.58 \\
\text { 3. } 19 \\
\text { 3. } 43 \\
\text { 3. } 66 \\
\text { 3. } 77 \\
3.99 \\
412 \\
419 \\
4.49 \\
4.6 \\
4.76 \\
5.1 \\
5.42 \\
5.5 \\
5.84 \\
6.0 \\
6.3\end{array}$ & $\begin{array}{l}\text { Nearest Si } \\
\text { Contact O } \\
\text { Nearest Na } \\
\text { Much } s \\
\text { Very little } s \\
\text { Very little } s \\
\text { Very little } s \text { but few paths } \\
\text { Very little } s \text {. } \\
\text { Appreciable } s \\
\text { Appreciable } s \\
\text { Much } s \\
\text { Appreciable } s \\
\text { Very little } s . \\
\text { Appreciable } s \\
\text { Very little } s \\
\text { Appreciable } s \text { but numerous } \\
\text { paths. } \\
\text { Very little } s . . \\
\text { Appreciable } s \text { but numerous } \\
\text { paths. } \\
\text { 4ppreciable } s \text { but numerous } \\
\text { paths. }\end{array}$ & $\left\{\begin{array}{l}2.2 \\
2.3 \\
2.6 \\
-3.4 \\
3.7 \\
4.0 \\
\hdashline 4.3 \\
\hdashline 4.9 \\
5.4 \\
5.8 \\
6.0 \\
6.3\end{array}\right.$ & $\begin{array}{c}\mathrm{a}(2.2) \\
2.4 \\
(2.9) \\
(3.2) \\
(3.4) \\
3.7 \\
(4.5) \\
4.8 \\
(5.5) \\
(5.8) \\
(6.1) \\
(6.3)\end{array}$ & $\begin{array}{c}2.4 \\
3.6 \\
4.7 \\
(5.5) \\
\end{array}$ \\
\hline
\end{tabular}

a Distances in parentheses were read from very small peaks.

TABLE 3. Radial distribution of ions around potassium in potash silicate glasses (angstroms)

\begin{tabular}{|c|c|c|c|c|c|c|c|}
\hline \multicolumn{4}{|c|}{ Computed possibilities } & \multirow[b]{2}{*}{$\begin{array}{l}\text { Remarks and estimates of } \\
\text { shielding }(s)\end{array}$} & \multirow[b]{2}{*}{$\begin{array}{l}\text { Estimated } \\
\text { peaks }\end{array}$} & \multicolumn{2}{|c|}{$\mathrm{X}$-ray evidence } \\
\hline To silicon & To oxygen & $\begin{array}{l}\text { To potas- } \\
\text { sium }\end{array}$ & $\begin{array}{l}\text { Vitron } \\
\text { model }\end{array}$ & & & $\begin{array}{l}\text { Hartlief } \\
{[5]}\end{array}$ & $\begin{array}{c}\text { Tilton } \\
\text { (Warren) }\end{array}$ \\
\hline $1 \mathrm{Si}_{1 s t}$ & $\begin{array}{ll}4 \mathrm{O}_{1 \mathrm{st}} \\
6 \mathrm{O}_{2 \mathrm{~d}} \\
3 \mathrm{O}_{3 \mathrm{~d}} \\
6 \mathrm{O}_{\text {th }} \\
\end{array}$ & $\begin{array}{l}6 \mathrm{~K}_{3 \mathrm{~d}} \\
\mathrm{~K}_{\text {ext }} \\
\mathrm{K}_{\text {ext }} \\
\mathrm{K}_{\text {ext }} \\
\mathrm{K}_{\text {ext }} \\
\mathrm{K}_{\text {ext }} \\
\mathrm{K}_{\text {ext }}\end{array}$ & $\begin{array}{l}\text { 2. } 65 \\
\text { 2. } 76 \\
2.81 \\
\text { 3. } 49 \\
\text { 3. } 93 \\
4.54 \\
4.5 \\
4.7 \\
5.0 \\
5.7 \\
5.9 \\
6.5 \pm 2\end{array}$ & $\begin{array}{l}\text { Contact } \mathrm{O} \\
\text { Nearest } \mathrm{Si} \\
\text { Nearest } \mathrm{K} \\
\text { Little } s \\
\text { Little } s \\
\text { Little } s \\
\text { Little } s \text { but few paths } \\
\text { Little } s \\
\text { Little } s \\
\text { Appreciable } s \\
\text { Appreciable } s \\
\text { Appreciable } s \text { but numerous } \\
\text { paths. }\end{array}$ & $\left\{\begin{array}{l}2.6 \\
2.7 \\
3.5 \\
3.9 \\
4.5 \\
4.8 \\
5.8 \\
6.5\end{array}\right.$ & $\begin{array}{c}2.3 \\
3.5 \\
4.7 \\
5.8 \\
\end{array}$ & $\begin{array}{c}2.3 \\
2.7 \\
3.7 \\
4.8 \\
6.2 \\
-10 \\
6\end{array}$ \\
\hline
\end{tabular}

\section{Effective Cage Saturation}

One of the most interesting questions about the structure of simple silicate glasses concerns the rate of deterioration of the silica network as oxygens are added, and another concerns the extent to which cations can be effectively inclosed in the cages.

\subsection{Chemical Attack and Water Solubility}

If the silica network begins to deteriorate immediately upon the addition of modifiers, one would expect an increased vulnerability of unshared oxygen to be immediately evidenced by rate of swelling in acids or solution in alkali. In fact, however, Hubbard [11] et al. have found such effects to be small or negligible below about $10-, 20$-, and 30 -mole percent of $\mathrm{K}_{2} \mathrm{O}, \mathrm{Na}_{2} \mathrm{O}$, and $\mathrm{Li}_{2} \mathrm{O}$, respectively, in $\mathrm{R}_{2} \mathrm{O}$ silicate binary glasses (see fig. 4). Tentatively, then, and in accord with geometrical conditions as discussed above, it may be suggested that at least 1 and sometimes 2 oxygens may go into each cage, together with the cations simultaneously introduced, because 1 such oxygen is provided for each cage at 16.7 -mole percent of $\mathrm{R}_{2} \mathrm{O}$, and at 28.6 percent there are available $2\left(\mathrm{R}_{2} \mathrm{O}\right)$ for every cage.

Some data on water solubility of these glasses were published by Dietzel and Sheybany [12]. From their curves (see fig. 5) it is seen that 16.7 percent of $\mathrm{K}_{2} \mathrm{O}, 23.1$ percent of $\mathrm{Na}_{2} \mathrm{O}$, and 28.6 percent of $\mathrm{Li}_{2} \mathrm{O}$ are reasonable estimates for maximal inclosure of oxygen and beginning deterioration of the network because of unshared oxygen. It will be noticed that the actual damages at the suggested critical percentages are greatest for $\mathrm{K}_{2} \mathrm{O}$ and smallest for $\mathrm{Li}_{2} \mathrm{O}$ in accord with the relative sizes of the respective cations. Hence it is suggested that mere size of cation is not negligible in expanding the volume of the network, and perhaps damaging it, even if all modifiers are inclosed in cages.

The same data by Hubbard [11] et al. on rate of chemical attack indicate that very serious damage to potash silicate glass can occur at mole percentages of modifier near 25 and to soda silicate glass near 35 . This accords with the idea that maximum inclosure of $\mathrm{K}$ ion is reached at not more than 28.6-percent $\mathrm{K}_{2} \mathrm{O}$ or $4 \mathrm{~K}$ per cage, and maximum inclosure of $\mathrm{Na}$ at 37.5-percent $\mathrm{Na}_{2} \mathrm{O}$ or $6 \mathrm{Na}$ per cage. The ater- 


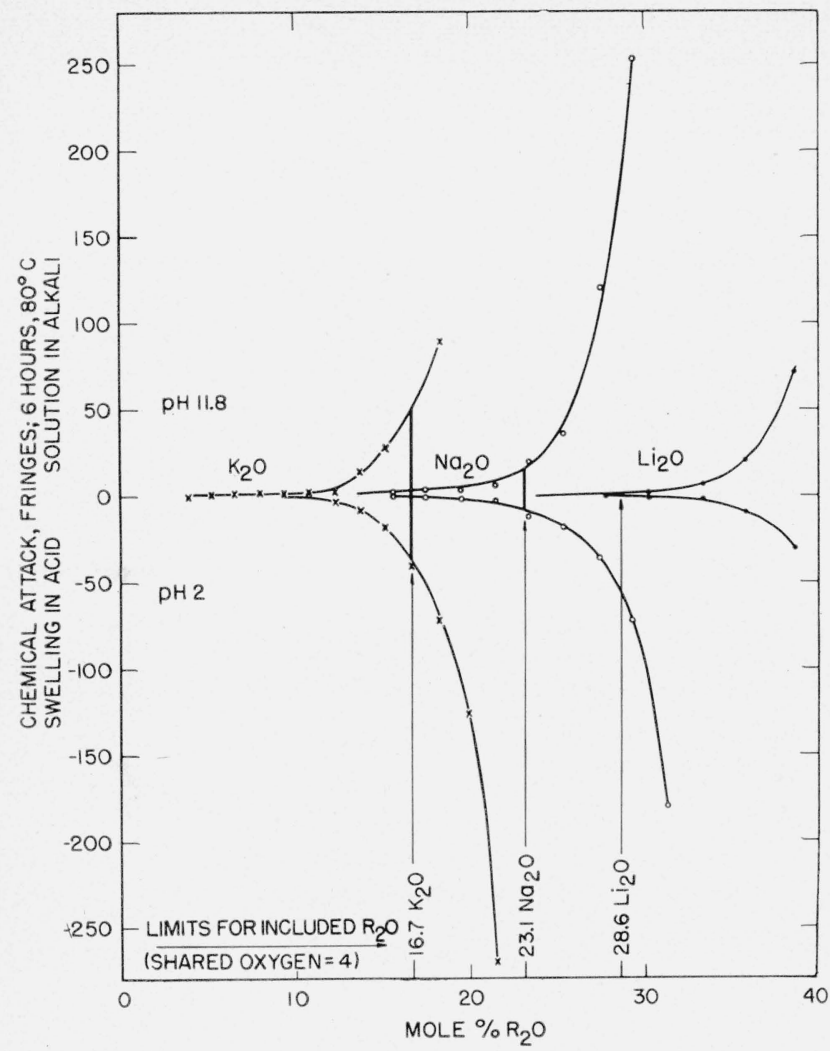

FiguRE 4. Chemical attack on alkali silicate glasses.

Data of Hubbard [11] et al. Noticeable rates of attack begin near the critical percentages for maximal inclosure of oxygen and beginning decrease in shared oxygen.

solubility curves indicate that these estimates of effective saturation are reasonable, and the estimates accord with the geometrical evidence deduced from the model.

\subsection{Volatilization}

Fortunately, it is possible to get more precise confirmations of the critical percentages of modifiers that will give saturation of the silica cages with cations. This is possible because of an extensive and remarkably significant series of experiments made at Sheffield, England, some 20 years ago by E. Preston and W. E. S. Turner [13] on the volatilization losses at high temperatures from simple binary melts including potash, soda, and lithia silicate glasses. Rate of volatilization of alkali from such melts would seem to be a property that might be especially sensitive to any alkali content over and above that necessary to saturate the cages of a network of silica, and also sensitive to temperature increases that are sufficiently high to damage a network and expose alkali that had previously been protectively inclosed. The results obtained by Preston and Turner, when plotted against compositions, did indeed show regions of particular interest but, unfortunately, the curves were analyzed primarily for evidence of the existence of chemical compounds in the glasses. The adverse criticism that followed has diverted attention from the data; and although the peculiarities have not been accept-

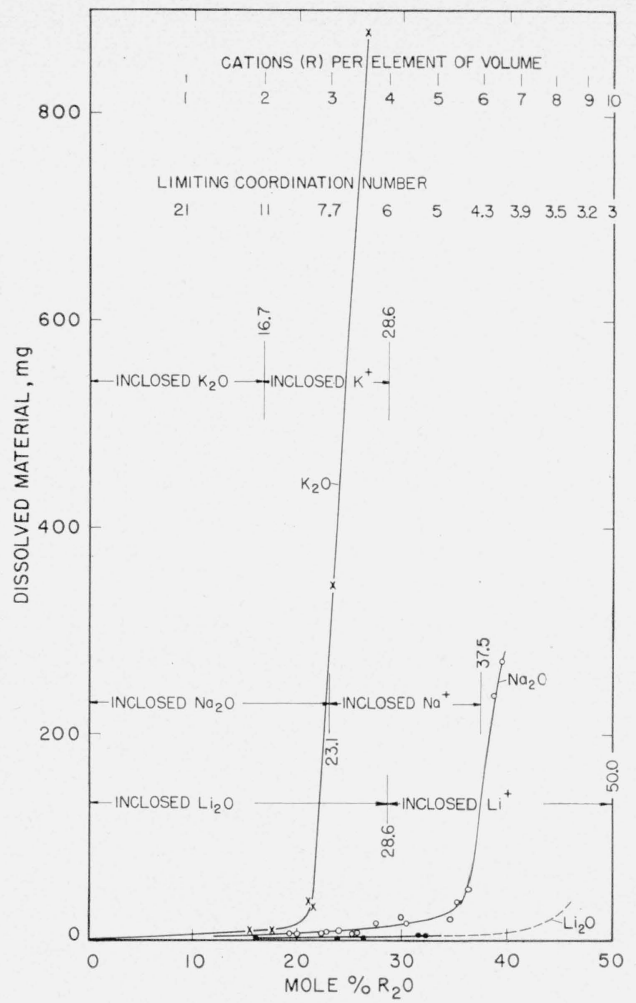

FIgURE 5. Water solubility of al)ali silicate glasses ( $1 \mathrm{hr}$, room temperature).

Data of Dietzel and Sheybany [12]. Near critical percentages of 16.7, 23.1, and 28.6 , where maximal oxygen is inclosed in the cages and the shared oxygen begins to decrease, there is beginning appreciable water solubility. The full saturation points of 28.6 and 37.5 occur near extremely high rates of solubility, and 50 percent for $\mathrm{Li}_{2} \mathrm{O}$ is not unreasonable.

ably explained, other possible uses of these data for interpretations concerning glass structure seem to have been overlooked.

Concerning these experiments Weyl [14] says, "The results were startling, and caused considerable controversial comment. *** For constant time the rate of volatilization changed abruptly with a continuous change of composition. *** aside from *** terminology and *** structural interpretation, the fact remains that the findings of W. E. S. Turner and his associates contradict the assumption of a continuous and completely random network."

For structural purposes it is not material whether the loss-composition curves are really straight lines or somewhat curved. The important matter is localization of the composition ranges within which a decided change in slope occurs. Their data do permit quantitative estimates of chemical compositions at or near which some important changes in structural conditions occur. For soda silicate glasses the critical region is certainly included between 32and 38-mole percent of soda, as shown in figure 6 . For glasses richer in soda, the rate of loss increases much more rapidly as soda content increases. This, essentially, must be the conclusion whether one looks at the original graph by Preston and Turner, ${ }^{2}$ or at

\footnotetext{
2 Figure 4, p, 338 of 1 st citation in literature reference [13].
} 


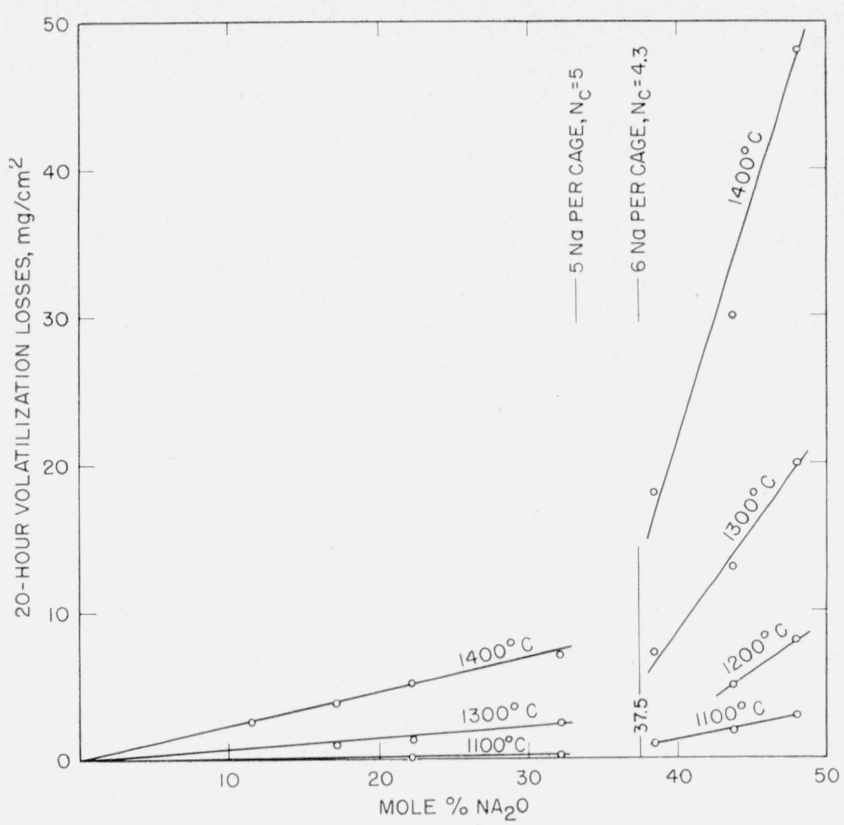

FIGURE 6. Losses in weight while soda silicate glasses are held at high temperature.

Data of Preston and Turner [13]. A concentration of 37.5 percent of $\mathrm{Na}_{2} \mathrm{O} \mathrm{i}{ }^{\mathrm{s}}$ Data of Preston and the net then contains 6 Na and above this indicated as critical. Each cage of the net then contains 6
percentage of soda the silica is supersaturated with modifier.

the graph as redrawn by Morey [15]; and the estimate would not be materially changed (although its locale might be accentuated) by consideration of the progressive changes in composition that are occurring during an experiment, especially for the minimum periods of $20 \mathrm{hrs}$, which alone will be considered here.

According to vitron theory there are two possible critical compositions within the region 32- to 38-mole percent $\mathrm{Na}_{2} \mathrm{O}$, namely 33.3 or 37.5 percent. These compositions are those at which there are available, respectively, 5 or 6 sodium atoms per cage. Six seems the more likely number for a critical condition because it is geometrically the maximum of $\mathrm{Na}$ ions that can be rationally accommodated within any deformed component cage of a vitron (except a veritable center cage - which alone can escape distortional deformation).

The interpretation from a similar exhibit of the corresponding evidence from potash silicate glasses heated at $1,400^{\circ} \mathrm{C}$ is less definite because, as will be shown presently, $1,400^{\circ}$ causes so much deterioration of the network of potash silica glasses that differences in losses above and below saturation are minimized. A corresponding exhibit that can be drawn for $1,300^{\circ}$ $\mathrm{C}^{3}$ would show some important change in conditions between glasses 34.74 and 39.60 percent (weight) of potash. The only possible critical composition that vitron theory offers is 28.6 -mole percent ( 38.6 weight), where 4 potassium atoms per cavity are available and, as already mentioned, 4 constitute geometrical saturation with rationally distributed potassium atoms.

The same result for the same potash silica series of glasses is obtained in a striking manner by plotting ratios of 20 -hour losses, $1,400^{\circ} \mathrm{C} / 1,300^{\circ} \mathrm{C}$, as in fig-

\footnotetext{
${ }_{3}$ See table VIII, p. 133 of 2 d citation in literature reference [13].
}

ure 7 where the rapid change in slope, and an inflection, ${ }^{4}$ show definitely the critical mole percentage 28.6 at which saturation of the cavities occurs. The high values on the leit side of figure 7 are caused by much greater temperature deterioration of the net from $1,300^{\circ}$ to $1,400^{\circ}$ as compared with $1,200^{\circ}$ to $1,300^{\circ} \mathrm{C}$.

From similar data for lithia silicate glasses it will be seen in figure 8 that 50 percent, which corresponds to 10 inclosed Li per cavity, is the critical composition of effective saturation with $\mathrm{Li}$ cations. Here it

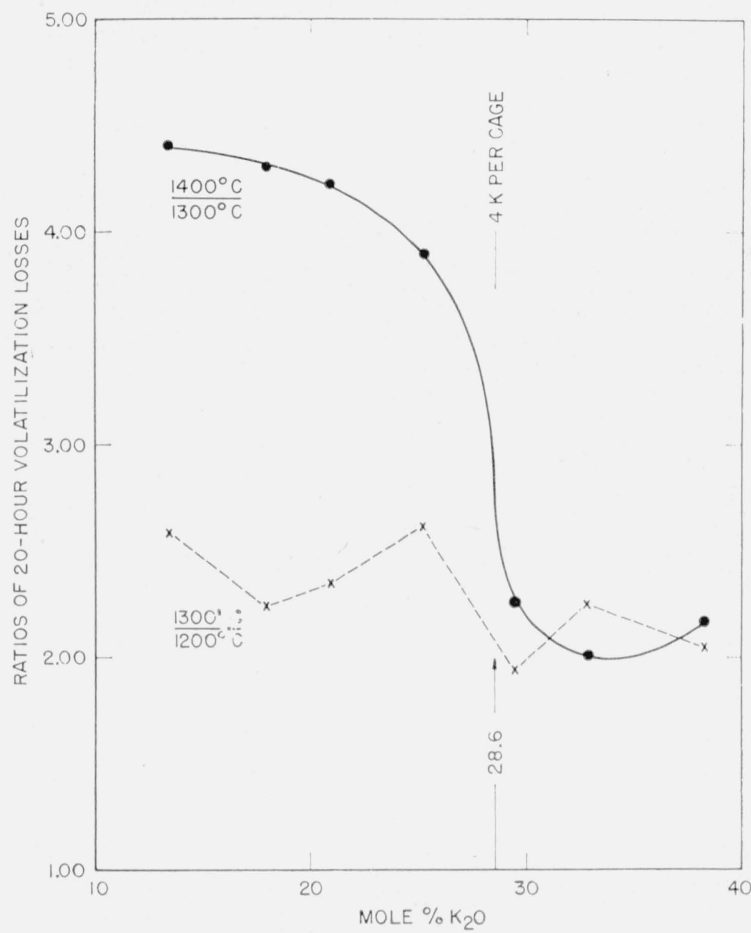

FIgure 7. Ratios of losses in weight while potash silicate glasses are held at high temperatures.

A concentration of 28.6 percent of $\mathrm{K}_{2} \mathrm{O}$ is indicated as critical, Each cage of the net then contains $4 \mathrm{~K}$ and above this percentage of potash the silica is supersaturated with modifier. From the left side it can be inferred that at some temperature between $1,300^{\circ}$ and $1,400^{\circ} \mathrm{C}$ the unsaturated network suffers very appreciable deterioration. From the right, where supersaturation has already damaged the network, it appears that a $\Delta t$ from $1,200^{\circ}$ to $1,300^{\circ} \mathrm{C}$ is relatively as effective as a $t$ from $1,300^{\circ}$ to $1,400^{\circ} \mathrm{C}$.

can be inferred that even a temperature increase from $1,200^{\circ}$ to $1,300^{\circ} \mathrm{C}$ causes appreciable deterioration of the net (such as occurred from $1,300^{\circ}$ to $1,400^{\circ} \mathrm{C}$ for potash silica glasses) and that between $1,300^{\circ}$ and $1,400^{\circ}$ the deterioration in $\mathrm{Li}_{2} \mathrm{O}$ glasses is still progressing. In contrast with the varying effects of progressively higher heat levels as evidenced in the left-hand portions of figures 6,7 , and 8 , it appears on the right that an increase of $100^{\circ} \mathrm{C}$ in holding temperature has a more nearly constant effect and approximately doubles the loss from supersaturated glasses, whether of soda, potash, or lithia, and regardless of the temperature level at least between $1,200^{\circ}$ and $1,400^{\circ} \mathrm{C}$.

Having selected tentative critical compositions for effective saturation it is now possible to compare

${ }_{4}$ This remarkable curve was published as figure 4, p. 134 of 2 d citation in literature reference [13] and seems never to have been explained. 


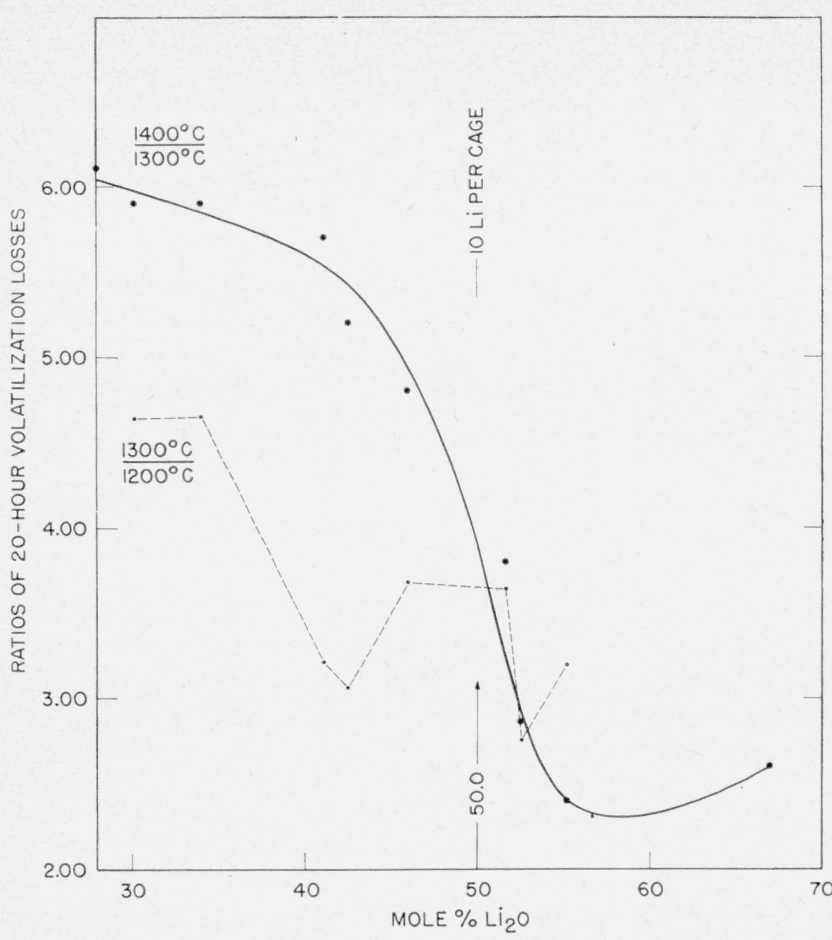

Figure 8. Ratios of losses in weight while lithia silicate glasses are held at high temperatures.

Above a critical concentration of 50-percent lithia, where $10 \mathrm{Li}$ are available for each cage of the network, the silica is supersaturated. A critical temperature for some deterioration of the unsaturated net of lithia silicate glasses seems to lie below $1,300^{\circ} \mathrm{C}$

equitably the losses by volatilization of the different alkalis after conversions from weights to moles of loss per unit concentration of modifier oxide. This is exhibited in figure 9 for $1,300^{\circ} \mathrm{C}$ and figure 10 for $1,400^{\circ} \mathrm{C}$ where positive abscissae represent supersaturation. In the writer's opinion the relative volatilities as they appear in figures 9 and 10 are more logical than is the case when the abscissae are plotted without regard to degree of saturation.

At $1,400^{\circ} \mathrm{C}$ lithia is found to be somewhat more volatile than potash, molecularly, but soda a little less so. At $1,300^{\circ} \mathrm{C}$ the differences between lithia and potash and soda seem negligible at low concentrations well below cation saturation, but at concentrations near and above saturation the soda is definitely less volatile than the other alkalis. In other words, a temperature of $1,400^{\circ} \mathrm{C}$, which damages the network, does not volatilize soda as easily as it does lithia and potash. Further, this effect is marked at moderate degrees of supersaturation even at $1,300^{\circ}$ where one would expect soda to be intermediate between the other alkalis. This seems to indicate that some of the soda is more firmly bound or inclosed in the silica net than either lithia or potash. The facts suggest that in general by mere inclosure of $\mathrm{R}_{2} \mathrm{O}$ it is very effectively protected, but that some "deep potential well" condition of some of the soda is so important that it continues to give protection to soda even when the net is somewhat deteriorated either by heat or damage because of reduction in shared oxygen.

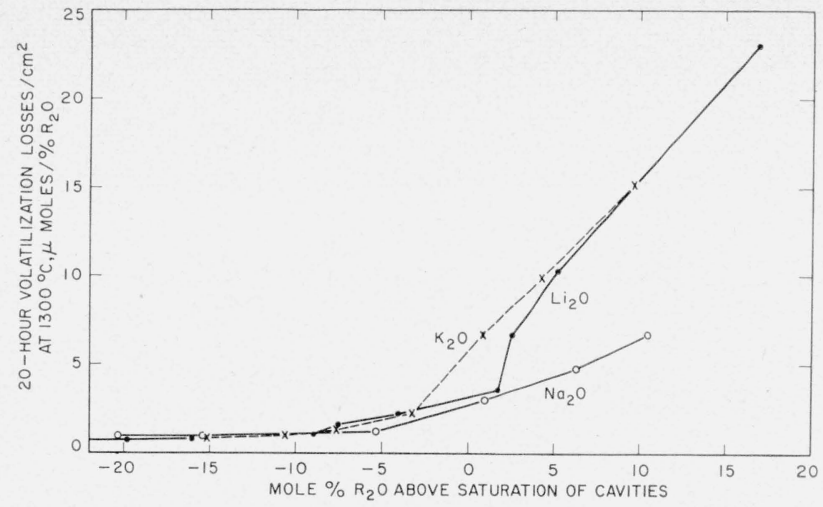

Figure 9. Volatilization losses at $1,300^{\circ} \mathrm{C}$ in micromoles per unit concentration at comparable degrees of saturation of network.

Lithia and potash are about equally volatile but soda somewhat less so at $1,300^{\circ}$ $\mathrm{C}$ and above saturation.

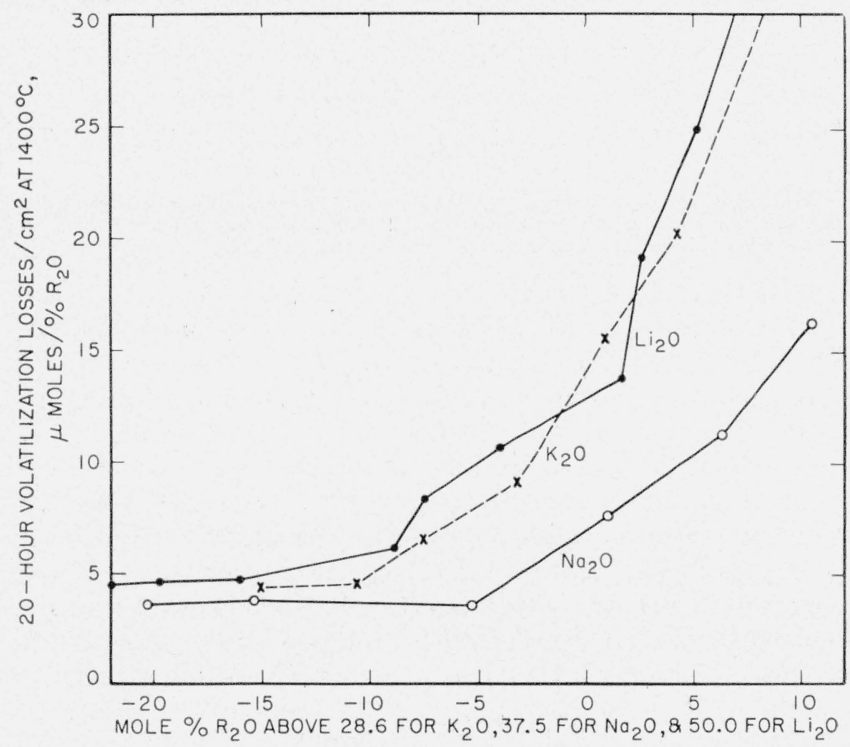

FIgURe 10. Volatilization losses at $1,400^{\circ} \mathrm{C}$.

Lithia is somewhat more volatile than potash and soda definitely less so. Soda seems to be more securely inclosed within the silica network than either lithia or potash and the increased stability is evidenced even at moderate degrees of supersaturation

\section{Molar Volume and Degree of Saturation}

An interesting feature of glass is the openness of its structure. In fused silica the volume of the voids is much greater than the volume of the ions, comprising about 62 percent of the total volume, whereas for the "most open" packing of equal spheres the voids are only 48 percent of the total. It has been said [16] that regular pentagonal dodecahedra have the largest possible cavities for a structure of interlaced tetrahedra. This openness in glass would seem to be particularly useful in studies of the structure of glasses containing known molecular proportions of nonsilica, especially if the idea of predominant randomness is supplanted by that of predominant order. 
A difficulty is the volume sensitivity of glasses to the temperatures employed in their annealing [27]. Permanent volume changes of as much as 1 percent are possible in annealed glasses and thus comparisons may have errors as large as 2 percent unless the annealings are "comparable." Just what constitutes comparability in annealings is not entirely clear but one can at least see that glasses are annealed at temperatures that are all comparably high or all low in their respective annealing ranges.

For a series of many simple soda silicate glasses, it is found that those with low-soda content have densities, $d$, or specific volumes, $V$, that, as functions of their composition, can be represented better by intersecting straight lines than by continuous curves. Some differences of opinion have been expressed about this, particularly when it was found that the intersections sometimes occurred where the constituent oxides were related approximately in simple proportions such as $1: 1,1: 2,1: 3$, etc. and no such compounds were known to exist. The use of segmented straight lines has persisted, however, and one outstanding example of their use was published by Huggins [2] who found intersections at several of the compositions to which vitron theory now (table 1) calls attention because integral numbers of sodium ions should at those points be expected in the dodecahedral cages of the network. The coefficients that Huggins gives for the computation of densities from his "structon" analysis may, therefore, to some extent, be regarded as analagous to coefficients that could be given for computing densities according to the number of cations per cage as deduced from a vitron analysis.

From the agreement between vitron and structon theories as set forth in table 1, it may be inferred that curves of specific volume versus composition for soda silicate glasses will show changes in slope near the points for integral numbers of sodium atoms per cage of the silica network. Presumably the same may be true for potash and lithia glasses.

In previous sections of this paper it has been suggested that conditions are somewhat more complicated and that some oxygen as well as cation can be inclosed in the cages of the silica network. From data on water solubility, swelling in acids, and solution in alkali, it was estimated that oxygen is inclosable up to mole percentages of 16.7 for $\mathrm{K}_{2} \mathrm{O}, 23.1$ for $\mathrm{Na}_{2} \mathrm{O}$ and 28.6 for $\mathrm{Li}_{2} \mathrm{O}$, and that added oxygens begin to produce unshared oxygen at some of the tetrahedral corners at about the compositions named. To test these estimates further and to show the results graphically on an open scale, it is desirable to plot only differences in volume between some function of composition and the volumes as computed from observed densities.

With such ideas and tentative structural data in mind, one can proceed to analyze data on the specific volumes computed from the measured densities of a series of simple binary silicate glasses provided all of them have been carefully and consistently annealed for comparison purposes. Data on such a series have been published by Young, Glaze, Faick, and Finn [17], particularly for soda and potash silicate glasses but including some lithia silicates, and these data will be used here. It is proposed to express all observations as gram molecular volumes of glass, $\mathrm{V}_{g}=w / d$, where $w$ is the molecular weight (linearly interpolated according to composition) and $d$ is observed density at room temperatures; and from these volumes to subtract a computed volume

$$
V_{c}=(1-p) V_{S}+x p V_{S}
$$

where $p$ is the mole fraction of the modifier oxide, $V_{S}=w / d=27.263 \mathrm{~cm}^{3}$ is the gram molecular volume attributable to the silica network (density 2.203), and $x$ is a volume replacement or expansion factor to be so determined that $V_{c}$ from eq (1) shall equal $V_{g}$ as observed when $\mathrm{R}_{2} \mathrm{O}$ replaces silica in very small amounts. In other words eq (1) is written to apply to the initial straight-line segments of curves when volume is plotted against modifier oxide beginning with 100-percent silica. This means that $x$ could be computed from the equation $x p V_{S}=p V_{R}$, if $V_{S}$ and $V_{R}$ are true partial molar volumes of silica ${ }^{5}$ and of oxide, and if $V_{R}$ be known.

It will be evident that if all $\mathrm{R}_{2} \mathrm{O}$ enters the cavities without distending the volume of the net, then $V_{R}$ must be zero and $x$ be zero. Or, if the rate of change in net expansion should be proportional to added $\mathrm{R}_{2} \mathrm{O}$, then eq (1) would continue to represent the observations and $V_{c}=V_{g}$ with an initially determined constant value of $x$, identical for $\mathrm{K}_{2} \mathrm{O}, \mathrm{Na}_{2} \mathrm{O}$, or $\mathrm{Li}_{2} \mathrm{O}$.

However, the actual values of $x$, computed from glasses with various small values of $p$, are 1.114, 0.644 , and 0.339 for $\mathrm{K}_{2} \mathrm{O}, \mathrm{Na}_{2} \mathrm{O}$, and $\mathrm{Li}_{2} \mathrm{O}$ silicate glasses, respectively. These replacement factors contrast decidedly with the values $x=0$ which are to be expected for small proportions of any $\mathrm{R}_{2} \mathrm{O}$ added to silica if all atoms of the oxides are inclosed in the cages without distending the volume of the net.

The diversity among these replacement factors, $x$, accords with the suggestion now being made that not only cations but some oxygens are inclosable in the cages of the network. This follows because if only cations are inclosed, and all oxygen added to the net, then the replacement factors, $x$, would for these $\mathrm{R}_{2} \mathrm{O}$ glasses depend chiefly on the rate of addition of oxygen, which does not differ among $\mathrm{R}_{2} \mathrm{O}$ oxides, and thus the values of $x$ would be nearly identical for each of the oxides.

It seems necessary, then, to conclude that even small proportions of modifier oxides, which presumably can be maximally inclosed in holes of the network, are distending the silica component, that is the network, whose volume is $(1-p) V_{S}$ to the extent $\Delta V_{g}=x p V_{S}$. Specifically (see fig. 11a), the replacement of silica by $\mathrm{K}_{2} \mathrm{O}$ to the extent of 10 percent causes 12 percent increase in volume of the residual (or $90 \%$ silica) net, but corresponding replacements with $\mathrm{Na}_{2} \mathrm{O}$ and $\mathrm{Li}_{2} \mathrm{O}$ will cause increases of only 7 and 4 percent, respectively. Otherwise stated, but perhaps less pertinently, replacements to the extent

5 Tentatively, $27 \mathrm{~cm}^{3}$ may be used as the partial molar volume of silica in both soda and potash silicate glasses at low-modifier content and room temperatures, as shown by Callow [18], and the same is true at $1,400^{\circ} \mathrm{C}$ as reported by White[19]. 
MODIFIER REPLACEMENT:

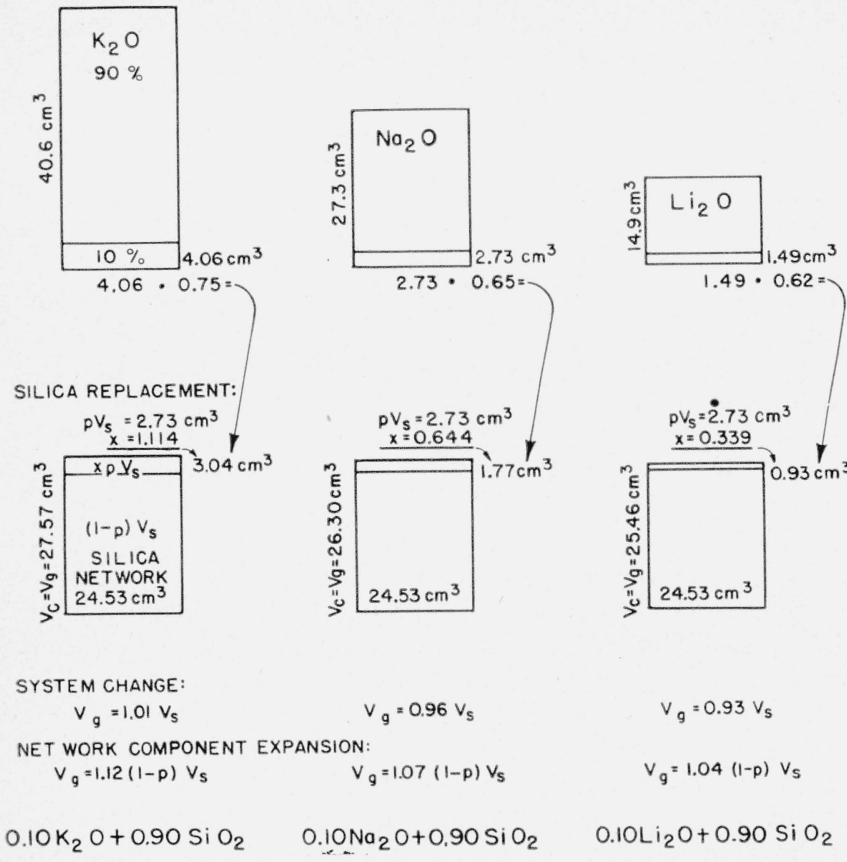

FIgure 11a. Changes in molar volume by additions of 10percent $\mathrm{R}_{2} \mathrm{O}$.

The most important facts are (1) apparent shrinkage of added modifier and (2) expansion of the silica network component, even for the small lithium atoms. (2) expansion of the silica network component, even for the small lithium atoms. inferred (1) that modifiers do penetrate the network and (2) that the network inferred (1) that modifiers do penetrate the network and (2) that the network expansion (even for small additions of modifier) cannot be due
added oxygens which are identical in number for each modifier.

of 10 percent cause an increase in total volume of the initial system ( $100 \%$ silica) of 1.1 percent with $\mathrm{K}_{2} \mathrm{O}$ but decreases of 3.5 and 6.6 percent with $\mathrm{Na}_{2} \mathrm{O}$ and $\mathrm{Li}_{2} \mathrm{O}$. Then the interpretation sometimes given is that the relatively stronger ionic potentials of sodium and lithium result in contractions of the networks. In view of prevailing ideas concerning the great strength and relative invariance of silica nets, the appropriateness of sucb an interpretation may be questioned.

As first stated, however, and if all additions go inside the silica net that is simultaneously formed, no contractual effect of the network is evident, even in the case of lithia silicate glass. In all three glasses the over-all effects on the net are expansional and the interpretation here suggested, on a vitron basis, is that all of the added oxides at these small proportions of nonsilica are inclosed in the cavities and that the content of oxides either strengthens the elemental dodecahedral volumes or by its mere presence restricts their deformability. This would result in reduced size limits for the growth of vitrons (clusters of elemental volumes), and increase the number and widths of the intersticial channels between vitrons. The three oxides, $\mathrm{K}_{2} \mathrm{O}, \mathrm{Na}_{2} \mathrm{O}, \mathrm{Li}_{2} \mathrm{O}$, are found to have this expansive effect in the ratios $44: 26: 14$ which correspond roughly to ratios of their gram molecular volumes, namely, 41:27:15, which can be estimated from the densities of these oxides at room temperatures.
The linear eq (1) yields good values for the volumes of only a few of these two-component glasses at the lower concentrations of nonsilica, and it is found that additional terms or a series of values for $x$ would be required in order to extend its application beyond values of $p$ larger than about 17 percent for $\mathrm{K}_{2} \mathrm{O}$, 23 percent for $\mathrm{Na}_{2} \mathrm{O}$, and 29 percent for $\mathrm{Li}_{2} \mathrm{O}$. These are the critical percentages near which it was concluded from solubility and chemical-attack data that maximal oxygen is inclosed.

The extent, $\Delta V$, of the failure of eq (1) has been evaluated as $\Delta V=V_{g}-V_{c}$ for the three glass types mentioned, using the data on densities and compositions as published by Young, Glaze, Faick, and Finn. [17] These increases in volume are plotted in figure $11 \mathrm{~b}$ to show that the stepwise nature of the increases is consistent with a thesis that changes in slope can occur at each composition corresponding to an integral number of cations per hole; also to show how nearly identical are the rates of increase in volume upon the addition of very diverse oxides.

For the intervals considered here, the points where slopes may change are at the percentages 16.7, $23.1,28.6,33.3,37.5$, and 41.1 corresponding to 2,3 , $4,5,6$, and 7 cations per elemental cage of volume.

Noticeable features of the curves in figure $11 \mathrm{~b}$ are the points at which the linear eq (1) becomes inadequate for computing volumes. Mention has already been made of these points near 17, 23, and 29 percent of $\mathrm{R}_{2} \mathrm{O}$ where the maximum inclosure of oxygen is reached. After that, the addition of modifier oxygen increases the oxygen of the network, unconnected tetrahedral corners can occur, and the effective volume of the network can be further expanded. In further accord with estimates of cation saturation in preceding sections of this paper, it is suggested (see fig. $11 \mathrm{~b}$ ) that 2 additional cations of potassium are inclosable (at $28.6 \% \mathrm{~K}_{2} \mathrm{O}$ ) with coordination lowered to 6 ; also that as many as 3 additional cations of sodium per cage can be inclosed (at $37.5 \% \quad \mathrm{Na}_{2} \mathrm{O}$ ) with coordination lowered to 4.3 ; and for $\mathrm{Li}_{2} \mathrm{O}$ possibly 6 additional cations are inclosable (at 50\%) to give a coordination number of 3 . These percentages of 29,38 , and 50 are to be considered as estimates of the compositions for which the cavities in these silicate binary glasses are effectively filled, and as limits beyond which the cations become much less firmly anchored within or protected by the silica framework. It will be noticed that the ranges from maximum inclosure of oxygen to maximum effective inclosure of cation are such that the upper limits for coordination extend on both sides of currently accepted estimates of normal coordination at 8 to 10 for $\mathrm{K}, 6$ for $\mathrm{Na}$, and 4 for $\mathrm{Li}$.

A noteworthy feature of figure $11 \mathrm{~b}$ is the near parallelism of these curves. This is interpreted as evidence that any progressive disruption of the network is largely independent of the size and nature of the modifier cations. This, of course, should be the case if the controlling factor is the rate at which oxygen is being added to cause progress in the disconnection of the tetrahedra. If, as suggested in this analysis, the numbers of inclosed oxygens average $1,1.5$, and 2 per element of volume, for $\mathrm{K}_{2} \mathrm{O}$, 




FIGURE 11b. Changes in volume of alkali silicate binary glasses with increased $\mathrm{R}_{2} \mathrm{O}$ content.

Data of Young, Glaze, Faick, and Finn [17]; displaced ordinates, common abscissae. At the critical percentages $16.7,23.1$, and 28.6 there is maximal inclosure of oxide modifier in the cages of the glass and the coordination numbers are large. At the critical percentages $28.6,37.5$, and 50.0 the cages are completely filled with oxide plus cations and the coordination is below normal. The rates of volume increase tend to become independent of the nature of the $\mathrm{R}_{2} \mathrm{O}$, probably because they depend mainly on the constant rate of addition of oxygen that is not inclosed and therefore weakens the network.

$\mathrm{Na}_{2} \mathrm{O}$, and $\mathrm{Li}_{2} \mathrm{O}$, respectively, then at percentages of $28.6,33.3$, and 37.5 the respective nets are only slightly, and about equally, disrupted to an average of 3.6 connected corners per tetrahedron. This is indicated in figure $11 \mathrm{~b}$ where dotted lateral lines $4.0,3.8,3.6$, etc. unite points of comparable degree of shared oxygen, that is degree of connection of the tetrahedra in the network.

\section{Electrical Resistance}

The sodium ion with a radius of $0.98 \mathrm{~A}$ is appreciably smaller than neon, radius $1.2 \mathrm{~A}$, which is the largest of the noble gases that readily passes through silica glass at any considerable rate. In general, other common network modifiers are larger than sodium and it is not surprising that the conductivity of glass at temperatures below annealing is commonly ascribed to migrations of the sodium ions. Question is sometimes raised concerning the potassium ion but its radius of $1.38 \mathrm{~A}$ approaches that of argon, $1.6 \mathrm{~A}$, which does not pass through silica except with great difficulty. Consequently it is not surprising that experiments have shown [20] that at temperatures below $600^{\circ} \mathrm{C}$ conduction by $\mathrm{K}$ ions is either negligible or excluded.

An extensive investigation of the electrical resistivity of soda silica glasses as a function of composition and temperature was made by Seddon, Tippett, and Turner [21]. Their results for logarithm of 
specific resistance at several temperatures between $250^{\circ}$ and $500^{\circ} \mathrm{C}$ have been replotted in figure 12 after conversions from weight to mole percentages of $\mathrm{Na}_{2} \mathrm{O}$. Data for $1,300^{\circ} \mathrm{C}$ from work by Endell and Hellbrügge [22] have been added. Similar work was done by Babcock [23] with good agreement in the regions of overlapping.

These curves show decreases in the resistances as soda is added, and this accords with a general deterioration of the network. Further, the curves show a possibility that the progressive deterioration may be nearly linear between certain definite percentages of $\mathrm{Na}_{2} \mathrm{O}$. The particular changes in slope explicitly noticed by Seddon, Tippett, and Turner near 37.5 percent $\mathrm{Na}_{2} \mathrm{O}$ at temperatures of $250^{\circ}$ to $400^{\circ} \mathrm{C}$ were confirmed by Babcock at $394^{\circ}$ to $727^{\circ} \mathrm{C}$ or higher; but at much higher temperatures, near $1,200^{\circ}$ and $1,300^{\circ} \mathrm{C}$, he definitely found no change in slope (in agreement with Endell and Hellbrügge). This is in general accord with the conclusions reached above in section 3.2 concerning high-temperature deterioration of the networks that can gradually obliterate the structural effects that can be observed at lower temperatures.

In addition to changes in slope of the low-temperature resistivity curves near the "saturation point" at 37.5 percent $\mathrm{Na}_{2} \mathrm{O}$, there is a definite change near 16.7 percent for the high temperatures. Possibly further work might confirm a less noticeable change at 28.6 percent. These special compositions of soda silicate glasses correspond to averages of 2,4 , and 6 sodium cations per dodecahedral element. Below $2 \mathrm{Na}$ per element of volume, soda silica glasses are not stable and devitrification readily occurs. At $6 \mathrm{Na}$ per element or 37.5 percent, it has already been suggested that the cages of the net are filled. At higher soda contents there is uninclosed soda and the disruption of the network begins to be a cause of instability. At the intermediate composition of 28.6 there are $4 \mathrm{Na}$ per element and the maximum coordination number becomes exactly 6 , which is probably nearly an optimum condition for soda silicate glasses. It is interesting to note that at the high temperature of $1,300^{\circ} \mathrm{C}$ the network is so much disrupted that resistance is low long before the cages in the network are filled at 37.5 percent soda, and only one special point, at 16.7 percent soda, remains in evidence. This is the point at which there may be a "deep potential well" distribution of the $\mathrm{Na}_{2} \mathrm{O}$ within the cages as suggested in figure 13, of this paper.

\section{Deep Potential Wells in Soda Silicate Glasses}

A soda content of 16.7-mole percent of modifier in $\mathrm{R}_{2} \mathrm{O}$ glasses gives 2 cations per dodecahedral element of volume of glass according to the vitron model, as shown by table 1 . If the cation is sodium, with radius $0.93 \AA$, the logical arrangement is that shown in figure 13 and it is apparent that a strengthened cage structure may result and the sodium atoms so placed may be more integrally related to the network structure than additional sodium or any other

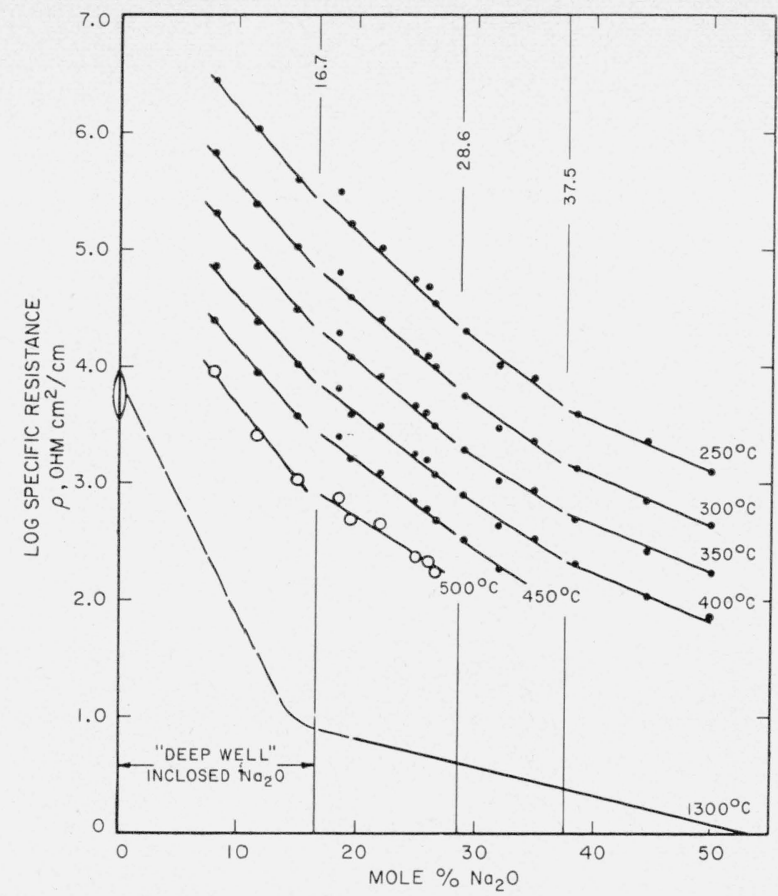

FIGURE 12. Effect of composition on specific resistance of soda silicate glasses,

Data of Seddon, Tippett, and Turner [21], after conversion to mole percent also curve from Endell $u$. Hellbrügge $[10,22]$ for $1,300^{\circ} \mathrm{C}$. At 16.7 -percent Na $\mathrm{O}_{2} \mathrm{O}$ each element of the vitrons has its complement of inclosed or "deep well" cations and at 28.6 percent the normal complement of $4 \mathrm{Na}$ with coordination number of 6. At 37.5 percent there are 6 Na ions per element, the cages in the net are prob6. At 37.5 percent there are $6 \mathrm{Na}$ ions per element, the cages in the net are probably completely filled, and the average number of connected corners of the
tetrahedra has fallen to 3.4 so that some disruption of the network has occurred. At $1,300^{\circ} \mathrm{C}$. only the "deep well" effect at 16.7 percent is noticeable. Even slightly increased disruption of the net by high temperatures seriously impairs resistance.

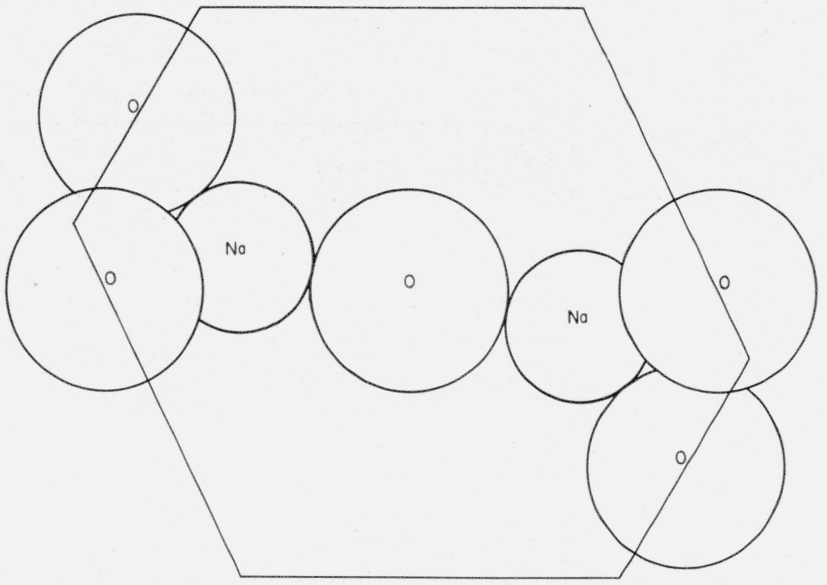

FIGURE 13. A uniquely metastable arrangement for a glass of 16.\%-mole percent soda and 83.3-percent silica.

See also figure 3 . The $\mathrm{Na}$ ions are each in closest possible contact $2.25 \mathrm{~A}$ between centers) with four oxygen halves and not far (3.4 A) from 6 others, The $\mathrm{Na}$ ions are as far from each other as possible $(4.55 \mathrm{~A}$ ) within the interior of dodecahedral element of a vitron. These distances accord with the differential dodecahedral element of a vitron. These distances accord with the differential
analyses of radial distribution curves deduced by Lukesh and by Dietzel from $\mathrm{X}$-ray diffraction patterns.

cation. References have been made to this unique geometrical arrangement in section 2.2 above; also in section 3.2 in discussing differential volatilization of soda and potash, and in section 5 regarding electrical resistivity of soda silicate glasses. 
In discussing electrical conductivity and dielectric losses, Stevels [24] distinguishes between $\mathrm{Na}$ ions that are "free" and others that are "enclosed". He considers that the enclosed ions lie in "deep potential holes", that annealing provides opportunity for a more thorough occupation of such positions (there is sometimes a factor of 3 between the conductivity of strained glass and the lower values for wellannealed glass), and that "the first $\mathrm{Na}$ ions added to a network are taken up in the deepest potential holes in which they stay with preference for energy reasons".

The idea that sodium ions situated as shown in figure 13 should resist migration may be related to the peculiarity found by Jenckel and Schwittman [25] near 17 percent $\mathrm{Na}_{2} \mathrm{O}$ when they determined temperatures of equifluidity of soda silicate glasses. Their curves of equifluidity have extremely well marked abrupt changes in slope as shown in figure 14 which is plotted from their data. Very rapid increases in viscosity as silica content increases are well known. Dietzel and Sheybany [12] in their discussions concerning the filling of voids with cations, have cited the work of Endell and Hellbrügge [22] on the viscosities of potash, soda, and lithia silicate glasses. Unfortunately, the viscosity seems

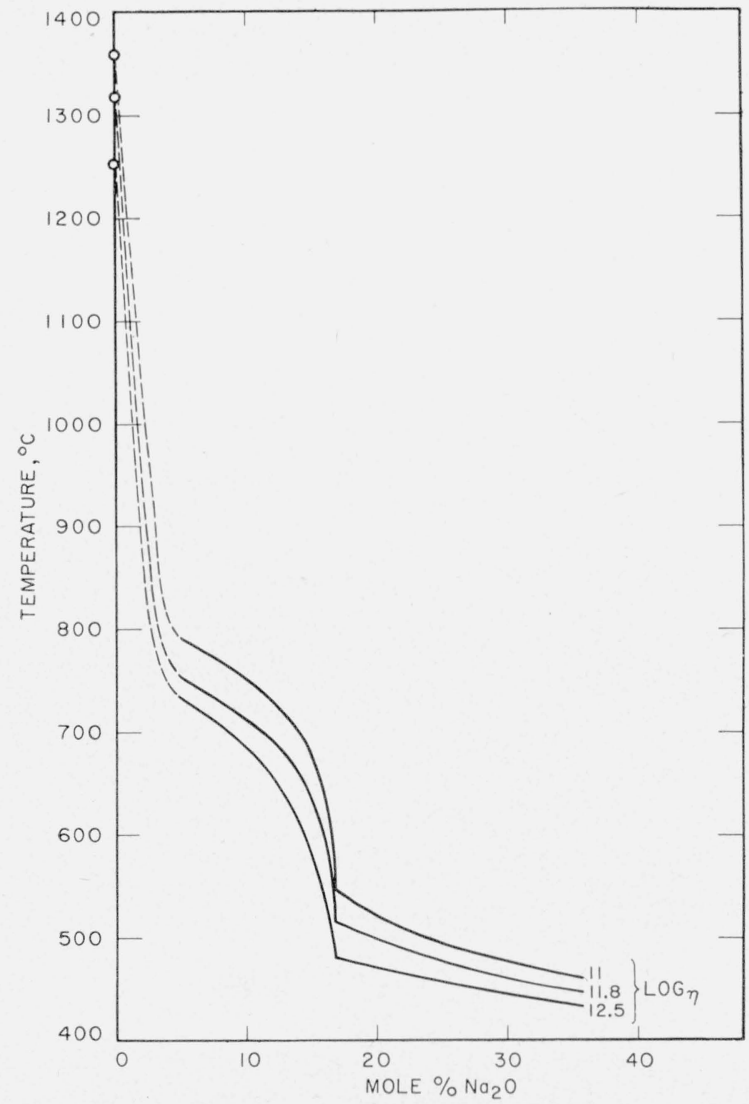

Figure 14. Temperatures for equiviscosity of soda silicate glasses.

Data by Jenckel and Schwittman [25] have been averaged, and points at 0 percent $\mathrm{Na} 2 \mathrm{O}$ are averages for two specimens measured by Volarovich and Leontieva [26]. At 16.7 percent $\mathrm{Na} 2 \mathrm{O}$ a critical demarkation may exist between stable glasses and those that crystallize so easily that viscosities are greatly stable glasses
increased. very sensitive to small degrees of crystallization and, aside from temperature difficulties, it has not seemed particularly useful to work with binary $\mathrm{R}_{2} \mathrm{O}$ glasses having large concentrations of $\mathrm{SiO}_{2}$. Jenckel and Schwittman, however, extended their fluidity measurements well into the conentrations that tend to crystallize and also to temperatures fairly low in the annealing ranges. The lower the temperatures at which they measured fluidity, the sharper was the cutoff point in $\mathrm{Na}_{2} \mathrm{O}$ content below which the fluidity decreased more or less abruptly, possibly on account of devitrification. Supposing it is incipient crystallization that caused sudden changes in the viscosity, it is interesting to ask, why this crystallization effect is so critical at approximately the composition of 16.7 -percent $\mathrm{Na}_{2} \mathrm{O}$. Does the deepwell condition so strengthen the cages and resist migrations as to prevent collapse in structure incident to and necessarily prerequisite to devitrification? If crystallization is not active why is there a sudden change in fluidity at this definite composition? Can it be that at low concentrations $\mathrm{Na}_{2} \mathrm{O}$ enters the cages only as a unit so that at all soda contents below 16.7 percent there will be some cages in which there are no cations? Such empty cages might deform more easily and thus be compatible with narrower intervitron channels and conducive to lower fluidities at temperatures in and above the annealing ranges.

\section{Conclusion}

In this paper it has been found geometrically possible that the beginning of deterioration of the silica network by addition of modifier oxides can be deferred up to 16.7-mole percent even for $\mathrm{K}_{2} \mathrm{O}$ and possibly 23.1 or 28.6 percent for $\mathrm{Na}_{2} \mathrm{O}$. Also from such considerations it is found that the maximum content of completely inclosed cation per cage is 4 of $\mathrm{K}$ or 6 of Na. The probable loci of these ions in the dodecahedral cages lead to radial distances between ions that agree well with data from differential analyses of diffraction pattern data.

From data on chemical attack and water solubility it appears that 16.7 percent of $\mathrm{K}_{2} \mathrm{O}, 23.1$ percent of $\mathrm{Na}_{2} \mathrm{O}$, and 28.6 percent of $\mathrm{Li}_{2} \mathrm{O}$ are reasonable estimates for maximal inclosure of oxygen and simultaneous beginning deterioration of the network because of unshared oxygen. From data on volatilization at high temperatures it is found that percentages of $28.6,37.5$, and 50 , corresponding to inclosures of 4,6 , and 10 ions of $\mathrm{K}, \mathrm{Na}$, and $\mathrm{Li}$, respectively, are fairly definitely indicated for full saturation of the cages.

Changes in the molar volumes of these alkali glasses as a function of $\mathrm{R}_{2} \mathrm{O}$ content are in accord with the idea that there may be structural-change points corresponding to some of the percentage compositions of $16.7,23.1,28.6,33.3,37.5$, and 41.1 where there are $2,3,4,5,6$, and 7 cations per cage or cavity of the network.

For sodium silicate glasses, the change in slope indicating cage saturation at 37.5-percent $\mathrm{Na}_{2} \mathrm{O}$ is detectable on curves of resitivity at low temperatures 
but not for temperatures near $1,300^{\circ} \mathrm{C}$ where temperature deterioration of the network may mask the saturation point. The deep-potential-well point at 16.7-percent $\mathrm{Na}_{2} \mathrm{O}$ probably becomes prominent above $400^{\circ} \mathrm{C}$ on curves of resistivity but is definitely less so at lower temperatures. This point at 16.7percent $\mathrm{Na}_{2} \mathrm{O}$ is very prominent on curves of equifluidity near annealing temperatures. Glasses richer in $\mathrm{SiO}_{2}$ devitrify very readily.

Thus it is apparent that considerable qualitative and some semiquantitative and intercorrelated evidence in support of the vitron theory of glass structure is given by analyses of existing data on propertycomposition curves of solubility, chemical attack, volatilization, molar volume, electrical resistance, and fluidity of alkali silicate binary glasses. It is concluded that further studies of this nature should be made when more varied, more extensive, and more accurate data are available.

\section{References}

[1] L. W. Tilton, J. Research NBS 59, 139 (1957) RP2782.

[2] M. L. Huggins, J. Opt. Soc. Am. 30, 421 (1940); J. Phys. Chem. 58, 1145 (1954).

[3] B. E. Warren and A. D. Loring, J. Am. Ceram. Soc. 18, $269(1935)$; B. E. Warren, H. Krutter, and O. Morningstar, J. Am. Ceram. Soc. 19, 202 (1936).

[4] B. E. Warren and J. Biscoe, J. Am. Ceram. Soc. 21, 259 (1938).

[5] G. Hartlief, Z. anorg. u. allgem. Chem. 238, 379 (1938); J. Biscoe, M. A. A. Druesne, and B. E. Warren, J. Am. Ceram. Soc. 24, 100 (1941).

[6] J. Biscoe, J. Am. Ceram. Soc. 24, 262 (1941).

[7] J. Biscoe and B. E. Warren, J. Am. Ceram. Soc. 21, 287 (1938); R. L. Green, J. Am. Ceram. Soc. 25, 83 (1942).
[8] J. Biscoe, A. G. Pincus, C. S. Smith, and B. E. Warren, J. Am. Ceram. Soc. 24, 116 (1941).

[9] J. S. Lukesh, Proc. Natl. Acad. Sci. 28, 278 (1942).

[10] A. Dietzel, Glastech. Ber. 22, 214 (1949).

[11] D. Hubbard, M. H. Black, S. F. Holley, and G. F. Rynders, J. Research NBS 46, 168 (1951) RP2189; D. Hubbard and G. W. Cleek, J. Research NBS 49, 267 (1952) RP2363.

[12] A. Dietzel and H. A. Sheybany, Verres et réfractaires 2, 63 (1948)

[13] E. Preston and W. E. S. Turner, J. Soc. Glass Technol. 16, 331 (1932); 17, 122 (1933); 18, 143 (1934).

[14] W. A. Weyl, J. Soc. Glass Technol. 35, 442 (1951).

[15] G. E. Morey, J. Am. Ceram. Soc. 17, 320 (1934).

[16] Eugène Poncelet, Verres et réfractaires 2, 208 (1948).

[17] J. C. Young, F. W. Glaze, C. A. Faick, and A. N. Finn; J. Research NBS 22, 453 (1939) RP1197.

[18] R. J. Callow, J. Soc. Glass Technol. 36, 137 (1952).

[19] Jack L. White, Ph. D. Dissertation, U. of Calif., p. 101 (1955) ; J. O'M. Bockris, J. W. Tomlinson, and J. L. White, Trans. Faraday Soc. 52, 306 (1956).

[20] R. Schwarz and J. Halberstadt, Z. anorg. u. allgem. Chem. 203, 365 (1932); 210, 286 (1933).

[21] E. Seddon, E. J. Tippett, and W. E. S. Turner, J. Soc. Glass Technol. 16, 474 (1932).

[22] K. Endell and H. Hellbrügge, Beiheft Nr. 38 zu der Z. VDGh. 1940; Z. angew. Chem. 53, 271 (1940).

[23] C. L. Babcock, J. Am. Ceram. Soc. 17, 329 (1934).

[24] J. M. Stevels, Progress in theory of physical properties of glass, p. 59, 67, 75, 79 (Elsevier, New York, N. Y., 1948).

[25] E. Jenckel and A. Schwittmann, Glastech. Ber. 16, 168 (1938).

[26] M. P. Volarovich and A. A. Leontieva, J. Soc. Glass Technol. 20, 139, 1036.

[27] L. W. Tilton, J. Soc. Glass Technol. 40, T338 (1956).

Washington, July 12, 1957. 